Results 130 cases met the case definition with an overall annual incidence of 5.04 cases per million children under 16 years.

London, East Midlands, West Midlands and Scotland had estimated incidences above the national incidence. Boys (91/130; $70 \%)$ were significantly more affected than girls (39/130; $30 \%)$ and the majority were of Black (44.6\%) and South Asian (36.2\%) ethnicity with a median age of 18 months. The commonest clinical presentations were bowed legs, swollen wrists and radiological rickets. Comorbidities included fractures $(15 / 130 ; 11.5 \%)$ hypocalcaemic seizures (11/130; 8.5\%;), and dilated cardiomyopathy $(4 / 130 ; 3 \%)$ Two children died of dilated cardiomyopathy from vitamin D deficiency. The commonest associated conditions were cows milk protein allergy $(19 / 51 ; 19 \%$; ) iron deficiency $(8 / 51 ; 7 \%)$ and eczema $(8 / 51$; $7 \%)$ At the time of diagnosis $77 \%$ of children were not receiving vitamin $\mathrm{D}$ supplements. 19 children had rickets despite being reported to be receiving appropriate supplementation. All confirmed radiological cases had either high parathyroid hormone and/or low phosphate. Following diagnosis, most clinicians initially prescribed treatment themselves, with huge variation in duration of prescriptions. In a further 10 cases, rickets was confirmed but excluded in the incidence analysis, for not meeting the case definition (specifically Vitamin $\mathrm{D}<25 \mathrm{OHnmol} / \mathrm{L}$ ), suggesting both dietary calcium deficiency and vitamin D insufficiency as role-players in the presentation of NR in the UK.

Conclusions NR continues to affect children in the UK with serious sequelae. Uptake of vitamin D supplementation remains low and constitutes a failure of current public health policy. A UK national policy focusing on vitamin D and calcium supplementation and adherence is required to eliminate this entirely preventable condition.

\section{REDUCED RATES OF JUVENILE ONSET RECURRENT RESPIRATORY PAPILLOMATOSIS IN AUSTRALIA AFTER IMPLEMENTATION OF A NATIONAL HPV VACCINATION PROGRAM}

\begin{abstract}
${ }^{1,2}{ }^{2}$ Z Zurynski, ${ }^{3} \mathrm{JML}$ Brotherton, ${ }^{4} \mathrm{D}$ Novakovic, ${ }^{4,5}$ ATL Cheng, ${ }^{2,6} \mathrm{R}$ Booy, ${ }^{7} \mathrm{R}$ Berkowitz, ${ }^{8} \mathrm{SM}$ Garland, ${ }^{1,2} \mathrm{E}$ Elliott, ${ }^{8} \mathrm{R}$ Black. ${ }^{1}$ Australian Paediatric Surveillance Unit, Kids Research Institute, The Children's Hospital at Westmead, Sydney, Australia; ${ }^{2}$ Sydney Medical School, Discipline of Child and Adolescent Health, The University of Sydney, Sydney Australia; ${ }^{3}$ National HPV Vaccination Program Register, VCS, East Melbourne and School of Population and Global Health, University of Melbourne, Melbourne, Australia; ${ }^{4}$ Sydney Medical School, The University of Sydney, Sydney, Australia; ${ }^{5}$ ENT Department, Children's Hospital at Westmead, Sydney, Australia; ${ }^{6}$ National Centre for Immunisation Research and Surveillance, Children's Hospital Westmead, Sydney, Australia; 'Otolaryngology Department, Royal Children's Hospital, Melbourne, Australia; ${ }^{8}$ Royal Women's Hospital, Department of Microbiology and Infectious Diseases, and Murdoch Children's Research Institute, Infection and Immunity Theme; and Department of Obstetrics and Gynaecology, University of Melbourne, Melbourne, Australia; ${ }^{8}$ Paediatric Otolaryngology Head and Neck Surgery, Lady Cilento Children's Hospital, Brisbane, Australia
\end{abstract}

10.1136/archdischild-2018-rcpch.485

Aims Juvenile onset Recurrent Respiratory Papillomatosis (JoRRP) is a rare chronic disease caused by human papillomavirus (HPV) types 6 and 11. Children with RRP require multiple surgical interventions; tracheostomy may be needed and sometimes the disease is fatal. Infections are now preventable through HPV vaccination. Following an extensive quadrivalent HPV vaccine catch-up program for females aged 12-26 years in 2007-2009, in Australia, we aimed to monitor the changes in incidence and demographics of JoRRP over time.

Methods The Australian Paediatric Surveillance Unit (APSU) conducted national surveillance for JRRoP using its well established reporting system. In addition to the $\sim 1450$ paediatricians who report to the APSU each month, paediatric otorhinolaryngologists were also enrolled in the APSU and offered HPV typing. We report findings for the five-year period to end 2016.

Results The average annual incidence rate was 0.0715 per 100000 children aged $<16$ years. The largest number of cases was reported in the first year, with decreasing annual frequency thereafter. The rate declined significantly from 0.163 per 100000 in 2012 to 0.024 per 100000 in 2016 $(p=0.034)$. Among the 15 incident cases $60 \%$ male, 60\% were first born children and 13 (87\%) were born vaginally. None of the mothers of these children had received the HPV vaccine before pregnancy, and $3(20 \%)$ of the mothers had a history of genital warts. Seven genotyped cases were positive for HPV including 4 that were HPV6 positive and 3 that were HPV11 positive.

Conclusion To our knowledge this is the first report internationally documenting decline in JoRRP incidence in children following a quadrivalent HPV vaccination program.

\section{THE NATIONAL CONGENITAL ANOMALY AND RARE DISEASE REGISTRATION SERVICE (NCARDRS): THE FIRST YEAR}

${ }^{1} \mathrm{M}$ Ward-Platt, ${ }^{2} \mathrm{~S}$ Stevens, ${ }^{2} \mathrm{~N}$ Miller. ${ }^{1}$ Royal Victoria Infirmary, Newcastle upon Tyne, UK; ${ }^{2}$ Public Health England, London, UK

10.1136/archdischild-2018-rcpch.486

Background Congenital anomalies (CA) cause around a fifth of infant deaths and are a major contributor to subsequent illness and disability. Regional registers of CA have existed for over 30 years but an effective national registration system has long been needed. More recently, in recognition that collectively Rare Diseases are thought to affect up to 3.5 million people in UK, rare disease registration has been planned which will align with parallel European initiatives.

Methods From April 2015 Public Health England launched NCARDRS, incorporating the 7 existing regional CA registers and the National Down Syndrome Cytogenetic Register. Those regions not previously covered (51\% of England) were added. A central database was developed for the accrual of new cases and into which to import data held in the pre-existing registers. New data sources for case ascertainment and import of supporting data, such as cytogenetic laboratory feeds, links to BadgerNet neonatal, and Hospital Episode data, have been developed. Pilot work and database development for Rare Disease ascertainment is ongoing. The analysis we report was based on data aggregated from 4 of the pre-existing NCARDRS regions.

Results There were 2905 cases with at least one congenital anomaly among 141474 (21\%) of births in England in 2015. CA accounted for $17 \%$ of infant deaths, half of which were from cardiac anomalies. Two thirds of anomalies were diagnosed prenatally; of those diagnosed postnatally for which there was information on timing, three quarters were diagnosed in the first postnatal week. Rates of non-genetic 
anomalies were significantly higher in mothers $<20$ years $(201$ per 10,000 [95\% CI: 164 to 245]) compared to the mean for all ages (147 per 10,000 [95\% CI: 141 to 154]). The birth prevalence of Edwards' syndrome increased on average by 1.2\% (95\% CI: $0.2 \%$ to $2.3 \%$ ) per year between 2005 and 2014.

Conclusion The development of an effective national CA registration system has proved feasible, and reporting for the whole of England should be possible from the 2017 birth cohort onwards. Accurate national surveillance and monitoring of congenital anomalies and rare diseases is set to become a powerful tool to address child morbidity and mortality.

\section{CONGENITAL TOXOPLASMOSIS - SURVEILLANCE AS KEY TO INFORM THE NATIONAL PREVENTION POLICY SWITZERLAND AS A TYPICAL EXAMPLE OF A LOW INCIDENCE COUNTRY}

C Rudin. Universitäts-Kinderspital beider Basel, Switzerland

\subsection{6/archdischild-2018-rcpch.487}

Background The results of a first national survey of symptomatic congenital toxoplasmosis using the Swiss Paediatric Surveillance Unit (SPSU) and data from two regional cord blood screening programs in western and northwestern Switzerland led to a change of paradigm in Switzerland in 2008, abandoning widespread non-systematic toxoplasmosis screening during pregnancy in our country.

Aim A second identical survey of symptomatic congenital toxoplasmosis was started in 2009 following abolition of toxoplasmosis screening during pregnancy with the aim to exclude any adverse impact of this change in paradigm on the incidence of congenital toxoplasmosis.

Results During the first survey period of 4 years between 1995 and 199815 proven cases of symptomatic congenital toxoplasmosis were reported, corresponding to 4 cases per year or an incidence of 1.36 per $100^{\prime} 000$ children of age $0-$ 15 in Switzerland. This exactly corresponded to our expectation calculated for Switzerland based on results of two cordblood screening programs in western parts of Switzerland (Basel and Lausanne), expecting at most 130 primary toxoplasmoses among 73'000 pregnant women, with 32 cases of congenital toxoplasmosis of which 4.5 were expected to be symptomatic each year.

During the second eight years' survey period between 2009 and 2017 only five children with symptomatic congenital toxoplasmosis were reported, which corresponds to less than one case per 100'000 children of age 0-15 in Switzerland.

Conclusion Despite abolishment of wide-spread non-systematic screening in 2008, incidence of congenital toxoplasmosis has continued to steadily decrease in Switzerland. Our data support abandoning toxoplasmosis screening programs in low-incidence countries such as Switzerland.

\section{INFLUENCING THE NATIONAL DEBATE ON MEDICAL ASSISTANCE IN DYING (MAID): LEVERAGING THE CANADIAN PAEDIATRIC SURVEILLANCE SYSTEM (CPSP) TO INFORM THE POSITION OF THE CANADIAN PAEDIATRIC SOCIETY (CPS)}

C Moore-Hepburn. Department of Paediatrics, University of Toronto, Toronto, Canada

\subsection{6/archdischild-2018-rcpch.488}

Aims In June 2016, Bill C-14 was enacted in the Canadian Parliament, allowing medical assistance in dying (MAID) for consenting adults with 'grievous and irremediable medical conditions' experiencing 'intolerable' suffering whose deaths are 'reasonably foreseeable'. Minor patients (both mature and 'never competent' minors) are currently excluded from the legislation. An independent review of the issue of minor patients and MAID was requested by Parliament.

As health professionals, politicians and the public grappled with this issue, never before formally contemplated in Canada, the Canadian Paediatric Surveillance Program (CPSP) sough to provide data on exploratory conversations and explicit requests for MAID from/for minor patients to inform the independent review.

Methods The CPSP is a joint program of the Public Health Agency of Canada and the Canadian Paediatric Society. The program conducts national surveillance into diseases that are high in disability, morbidity and economic costs to society, despite their low frequency. The CPSP surveys over 2500 paediatricians and paediatric subspecialists each month to monitor rare diseases, conditions and complications in Canadian children.

A one-time survey was sent to all CPSP participants in May 2016. The survey tool can be accessed at www.cpsp.cps.ca/ surveillance.

Results The survey response rate was $40 \%$. Over one-third of participants reported they provide end-of-life or palliative care (370;35\%).

Exploratory discussions with minor patients about MAID were reported by 35 participants, representing 60 patients, the majority of whom were 14-18 years of age. Nine (9) participants recalled an explicit request for MAID, representing 17 minors.

Exploratory discussions with patients about MAID, on behalf of minor patients, were reported by 118 participants, representing 419 minor patients, the majority of whom were under 1 year of age. Forty-five (45) participants recalled an explicit request for MAID, representing 91 parents, the majority of whom had children under 1 year.

Conclusion CPSP participants from across Canada reported exploratory conversations about and explicit requests for MAID from both minors and parents. Discussion with and explicit requests from parents outnumber those by minors by more than five to one.

This study represents an important and innovative use of a paediatric surveillance system to inform a national conversation on a complex emerging ethical issue. 